\title{
Evaluating the suitability of the SWAN/COSMO-2 model system to simulate short-crested surface waves for a narrow lake with complex bathymetry
}

\author{
Michael GraF $^{1 * *}$, Michael Sprenger ${ }^{1}$, Ulrike LohmanN ${ }^{1}$, Christian SeibT $^{2}$ and \\ HILMAR HOFMANN ${ }^{2}$
}

${ }^{1}$ ETH Zurich, Institute for Atmospheric and Climate Science, Switzerland

${ }^{2}$ University of Konstanz, Limnological Institute, Germany

(Manuscript received April 27, 2012; in revised form December 6, 2012; accepted February 10, 2013)

\begin{abstract}
The spectral wave model SWAN (Simulating Waves Nearshore) was applied to Lake Zurich, a narrow preAlpine lake in Switzerland. The aim of the study is to investigate whether the model system consisting of SWAN and the numerical weather prediction model COSMO-2 is a suitable tool for wave forecasts for the pre-Alpine Lake Zurich. SWAN is able to simulate short-crested wind-generated surface waves. The model was forced with a time varying wind field taken from COSMO-2 with hourly outputs. Model simulations were compared with measured wave data at one near-shore site during a frontal passage associated with strong on-shore winds. The overall course of the measured wave height is well captured in the SWAN simulation: the wave amplitude significantly increases during the frontal passage followed by a transient drop in amplitude. The wave pattern on Lake Zurich is quite complex. It strongly depends on the inherent variability of the wind field and on the external forcing due to the surrounding complex topography. The influence of the temporal wind resolution is further studied with two sensitivity experiments. The first one considers a low-pass filtered wind field, based on a 2-h running mean of COSMO-2 output, and the second experiment uses simple synthetic gusts, which are implemented into the SWAN model and take into account short-term fluctuations of wind speed at $1-\mathrm{sec}$ resolution. The wave field significantly differs for the $1-\mathrm{h}$ and 2-h simulations, but is only negligibly affected by the gusts.
\end{abstract}

Keywords: surface wave forecast, wind fluctuations, complex topography.

\section{Introduction}

Wind-generated short-crested surface waves play an important role for biological, chemical, erosive and sedimentative processes in lakes. Further, they are of interest for shipping companies, athletes and tourists. A specific topic concerning Lake Zurich and other pre-Alpine lakes is the erosion of historic palafitte settlements by waves ${ }^{1}$. For these reasons, a reliable wave simulation is highly desirable, which allows assessing the exposition of these sites to waves depending on season, weather regime and interannual variability.

Early numerical wave models produced a single wave height and period at each grid point, using a direct relationship between the local wind speed and the wave height and period (from TOLMAN et al., 2002). An important advance was the introduction of the concept of a wave spectrum by PIERSON et al. (1955), where the wave

\footnotetext{
${ }^{*}$ Corresponding author: Michael A. Graf, Institute for Atmospheric and Climate Science, ETH Zurich, 8092 Zurich, Switzerland, e-mail: michael_arthur_graf@bluewin.ch

${ }^{1}$ see http://www.erosion-und-denkmalschutz-bodensee-zuerichsee.eu for further details
}

activity is decomposed into a manifold of individual wave trains. The next fundamental step was made by GELCI et al. $(1956,1957)$ who introduced the concept of spectral transport equation, which became essential for the later development of spectral wave models (from KOMEN, 2004). Since the work of GELCI et al. (1956, 1957), ocean wave models are generally based on a spectral energy or so-called 'action balance equation' (TOLMAN and CHALIKOV, 1996). The classification of different spectral models is mainly based on the treatment of the nonlinear interaction terms in the action balance equation (TOLMAN et al., 2002). The first-generation models were very simple and did not take nonlinear interactions into account or did so in a coarse way. The second-generation models did take them into account, but only through parameterizations. Finally, in the third-generation models, an explicit source term for the nonlinear interactions is included, using the method developed by HASSELMANN et al. (1985) (from FRADON et al., 2000).

The first operational wave forecasts were made in preparation for the Normandy invasion of World War II in 1944 (TOLMAN et al., 2002), culminating in the work of SVERDRUP and MUNK (1947). Whereas these forecasts relied heavily on the forecaster's experience, 
the first computer-generated wave forecasts were made in July 1956 at the Joint Numerical Weather Prediction Unit (JNWPU). These prognoses were based on a $1000-\mathrm{hPa}$ wind forecast also calculated at JNWPU (HUBERT, 1957), which then were fed into the first third-generation wave model WAM (WAMDIG, 1988). The application range of the model is restricted to larger scales with a grid resolution of about $100 \mathrm{~km}$ (BOOIJ et al., 1999). WAM is used operationally since 1991 at the European Centre for Medium-Range Weather Forecasts (ECMWF), where a global forecast of ocean waves over a period of 10 days is generated. Nowadays, the model is driven by $10-\mathrm{m}$ winds from the ECMWF atmospheric model (JANSSEN et al., 1997).

The aim of this study is to investigate whether the model system consisting of the models SWAN and COSMO-2 is a suitable tool for wave forecasts for the pre-Alpine Lake Zurich, i.e. on a scale much smaller than for the ocean models mentioned above. For instance, presently no model-based wave forecast is provided for Swiss lakes. Essentially only wind forecasts are given, which then could be used to 'subjectively' guess wave fields. As a benefit of a model-based forecast, wave distributions and amplitudes over a whole lake could be determined.

In particular, three specific aspects will be addressed in the study: (a) a wave model will be run for three case studies on Lake Zurich within its complex surrounding topography. Special focus will be given to the passage of a cold front, which goes along with a pronounced wind surge. Two additional cases will briefly be discussed to see how other typical weather conditions affect the wave forecasts; (b) the model simulations are compared with high-resolution measurements of the surface wave field at a single station; (c) the time resolution of the driving surface winds and their impact on the wave forecasts is investigated, culminating in a simple simulation of wind gusts implemented into the wave model.

There are several challenges to be overcome in this study. First, the wave simulations are applied to Lake Zurich, a postglacial lake with an elongated shape and an area of $88 \mathrm{~km}^{2}$. In the northern part, it exhibits a steep, fjord-like bathymetry (see Fig. 1) with a maximum water depth of $136 \mathrm{~m}$. The eastern part of the lake is dynamically separated from the western part. The lake is embedded in rather complex terrain, situated between two hill ranges north of the Alps. Pioneering studies considering Lake Zurich mainly focus on barotropic surface seiches as well as internal seiches (HUTTER, 1983; HORN et al., 1986, MORTIMER and HORN, 1982). In our study, where the focus is on wind-generated surface waves, a high-resolution wave model needs to be applied. The model used in this study is SWAN (Simulating Waves Nearshore; HOLTHUIJSEN et al., 2009), a widely used third-generation wind-wave model (JIN and JI, 2001). It is specifically designed for application in coastal areas with horizontal scales less than 20-30 km and water depths less than 20-30 m (BOOIJ et al.,1999). However, SWAN can be used on any scale relevant for wind-generated surface

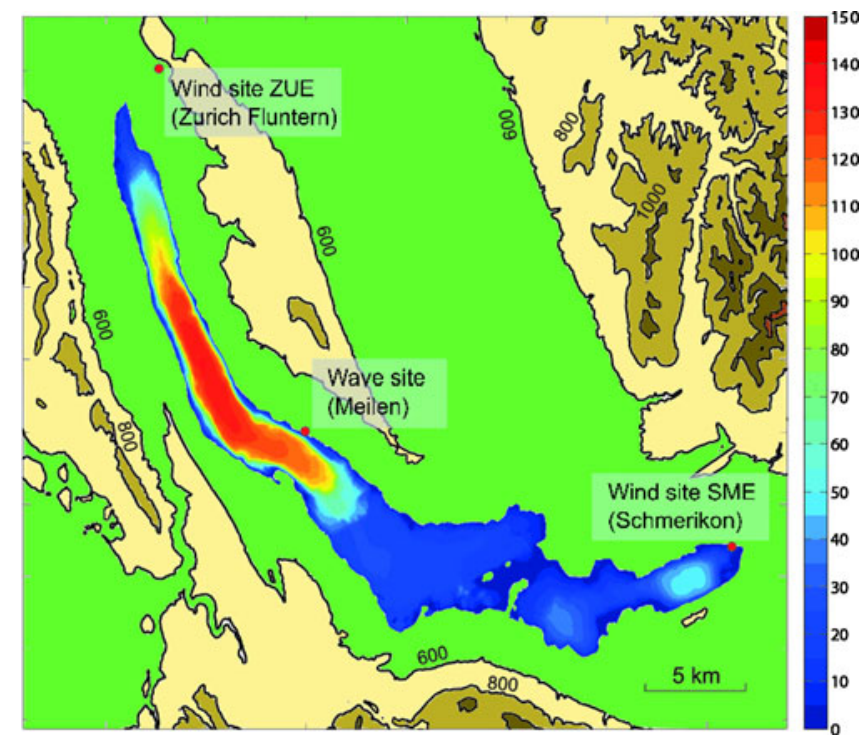

Figure 1: Bathymetry of the Lake Zurich with depth in $\mathrm{m}$ (colour shaded). The orographic height (in meters above sea level) of the surrounding area is displayed with colour-filled contours in $200 \mathrm{~m}$ steps from $600 \mathrm{~m}$ to $1200 \mathrm{~m}$. The red dots mark the position of the wind and wave measurement sites.

gravity waves (HOLTHUIJSEN et al., 2009). The model was applied on coastal areas (RIS et al., 1999; OU et al., 2002), estuaries (CHEN et al., 2005), bays (ROGERS et al., 2003) and large lakes (ROGERS et al., 2003; JIN and JI, 2001). It is also used on Lake of Constance (see http:// www.bodenseeonline.de).

A second challenge is related to the surface wind fields, which constitute the primary external driving force for the wave model. The wind field is one of the main factors determining the accuracy in a numerical wave model (CAVALERI and Rizzoli, 1981; KOMEN et al., 1994; LIU et al., 2002). Therefore, the focus of this study is placed on wind input data. In other research projects using wave models, wind input data are idealized (BOOIJ et al., 1999; TOLMAN, 1992), determined from measurements of nearby stations (RIS et al., 1999; JIN and JI, 2001; CHEN et al. 2005) or derived from numerical weather prediction (NWP) models (JANSSEN et al., 1997; SHIMADA et al., 2008; HOWARD et al., 2009). The horizontal resolution of the NWP models and therefore of the driving wind fields range from $16 \mathrm{~km}$ for global circulation models ${ }^{2}$ to $1 \mathrm{~km}$ for regional highresolution models (ROBERTS and LEAN, 2008). In a study of HOWARD et al. (2009), the influence of the NWP model's resolution on a coupled wind-wave model was tested. For this reason a high-resolution NWP model with a horizontal grid size of $1.5 \mathrm{~km}$ was applied to a region near the coast of Florida. Their results indicate that the horizontal resolution does not significantly influence the accuracy of the wave model. However, the terrain in the region investigated is rather flat and not comparable

${ }^{2}$ see http://www.ecmwf.int/products/changes/horizontal resolution 2009/ 
with the complex topography in this study. Furthermore the NWP models used in most studies have generally a coarse resolution and thus are not applicable for small regions and complex topography. For this reason we use input data derived from the high-resolution numerical weather model COSMO-2, which is operationally used by the Swiss national weather service (www.meteoswiss.ch). It provides hourly wind data at a 2.2-km horizontal resolution.

The time resolution of the driving NWP models leads to a third research question. Wind input data used in wave models are based on mean NWP winds at e.g. hourly intervals. In between, typically linearly interpolated winds are used to drive the wave models. However, the assumption of a linear wind evolution over a certain time period, e.g. during one hour in this study, is not realistic. Winds, in particular with gusts, exhibit short-term fluctuations in speed and direction (ÁGÚSTSSON and ÓlAFSSON, 2009; BRASSEUR, 2001). Previous studies in oceanic regions showed that gustiness has a significant impact on the wave field (CAVALERI and BURGERS, 1992; JANSSEN, 2004). Thus, the current study will investigate if gustiness has a relevant influence on surface waves on Lake Zurich.

The outline of the paper is as follows. Section 2 describes the configuration of the numerical wave model SWAN, the input data (bathymetry and NWP winds) and the in-situ measurements used for the validation. In section 3 a hindcast simulation for the cold frontal passage is studied in detail. This is complemented in section 4 with two additional cases, presented in less detail. All simulations are compared qualitatively and quantitatively with in-situ measurements at one site and sensitivity studies regarding the temporal resolution of the input wind fields are performed. Finally, conclusions are given in section 5 .

\section{Data and methodology}

\subsection{The SWAN wave model}

The numerical simulations of surface waves were realized with the SWAN model (BoOIJ et al., 1996). In this study we utilized version 40.72 (more details about this version can be obtained from the manual from HOLTHUIJSEN et al., 2009). "SWAN is a third-generation wave model that computes random, short-crested windgenerated waves in coastal regions and inland waters"3. It is a fully spectral wave model (for all directions and wave lengths) and is based on a spectral action balance equation (TOLMAN and CHALIKOV, 1996) from which propagation, refraction, shoaling, generation and dissipation of waves as well as nonlinear wave-wave interaction can be calculated from the following equation

$$
\frac{D F}{D t}=S_{i n}+S_{n l}+S_{d s}
$$

see http://www.swan.tudelft.nl
"The left hand side of this equation describes changes in the local wave spectrum $\mathrm{F}$ due to conservative and linear propagation of the wave energy of individual spectral components with their group velocity (and sometimes also due to the effects of externally prescribed mean currents). The right hand side represents a combination of non-conservative sources and sinks of wave energy, such as the wind input $\left(S_{i n}\right)$; dissipation due to wave breaking $\left(S_{d s}\right)$; other (mostly shallow water) processes and a term $S_{n l}$ representing the transfer of energy due to nonlinear interactions between the spectral wave components" (from TOLMAN, 2002).

The calculations are executed on a regular, rectangular grid with a spatial resolution of $200 \mathrm{~m}$ x $200 \mathrm{~m}$. A time step of one minute is used in order to obtain a realistic wave growth (see Appendix B). The spectral range is set to values between $0.05 \mathrm{~Hz}$ and $3.0 \mathrm{~Hz}$ (which corresponds to wavelengths between 624 and $0.17 \mathrm{~m}$ in deep water). The upper threshold of $3 \mathrm{~Hz}$ was chosen to consider also small wave heights in the simulations (see Appendix B). In Lake Zurich waves with wavelengths $>624 \mathrm{~m}$ can be observed but are caused by barotropic surface seiches (HUTTER, 1983), which cannot be simulated with the SWAN model. In the selection of the spectral range, as well for the other settings, we closely follow the study of SEIBT et al. (2013) for Lake of Constance: They argue that the frequency range of the wave spectrum must "be adjusted to the conditions in small to medium-sized lakes and therefore includes higher frequencies than are typically employed in coastal applications".

The utilized numerical scheme is the first-order BSBT (backward space, backward time) scheme. Linear (CAVAlERI and MALANOTTE-RIzZOLI, 1981) and exponential wave growth (KOMEN et al., 1984) are accounted for. Furthermore, the model includes the physical processes of refraction, deep-induced wave-breaking, whitecapping, bottom friction and nonlinear wave-wave interactions of triads and quadruplets (see HOLTHUIJSEN, 2007). More specific details of the setup can be found in SEIBT et al. (2013).

\subsection{Surface winds and bathymetry}

The model SWAN needs two external data sources: bathymetry and surface winds. The original bathymetry of Lake Zurich has a spatial resolution of $25 \mathrm{~m}$ (Fig. 1) and was then interpolated to the computational grid of SWAN. Data were provided by the national Swiss geoinformation center (see http://www.swisstopo.ch for further information on the quality of the data sets).

The wind data were extracted from the numerical weather prediction (NWP) model COSMO-2 (see http://www.cosmo-model.org), which is operationally run at the national Swiss weather service. COSMO-2 is a non-hydrostatic limited-area model with a spatial resolution of $2.2 \mathrm{~km}$ and serves hourly outputs (DOMS and SCHÄTTLER, 2002; SCHÄTTLER et al., 2009). The horizontal resolution allows the model to adequately resolve 
the complex topography of the pre-Alpine area (Fig. 1). However, the quality of COSMO-2 forecasts varies significantly and depends on the weather situation (see e.g. HUG et al., 2010). The SWAN wave prediction is driven by the zonal and meridional components of the wind data at $10 \mathrm{~m}$ above the surface, where the hourly wind output data are the instantaneous values of the NWP simulation at that time. For the gust simulation in SWAN (see section 3.2) also peak wind data were extracted from COSMO-2. These peak values of wind speed are derived from the gust parameterization of COSMO-2. They correspond to the maximum wind gust within the preceding hour. COSMO-2 includes an advanced planetary boundary layer (PBL) parameterization using a one-dimensional scheme (in the vertical) with a 2.5 order turbulence closure following the Mellor and Yamada notation (MELLOR and YAMADA, 1974; RASCHENDORFER, 2007). The maximum turbulent gusts at $10 \mathrm{~m}$ above the ground are derived from the turbulence state in the atmospheric boundary layer, using the absolute speed of the near-surface mean wind and its standard deviation (SCHULZ, 2008).

The grid resolution of $2.2 \mathrm{~km}$ of the COSMO-2 is state-of-the-art for high-resolution NWP models. COSMO-2 provides 20 grid points along the lake surface, allowing a sufficient representation of larger-scale wind features over the lake. For instance, when passing from land to sea, or lake water, the wind speed tends to increase. It typically doubles within a certain distance. This distance is in the order of 1,2 or more kilometers for wind speed of a few $\mathrm{m} / \mathrm{s}$. Hence, the wind is really changing continuously across the lake, and this might not be well modeled by COSMO-2. Additionally, the surrounding complex topography influences the wind field on the lake. Still, the purpose of the current study is to investigate the suitability of wind fields from nowadays high-resolution NWP models as input for wave simulations.

COSMO-2 wind data are compared to two local meteorological stations (ANETZ) around Lake Zurich [Zurich-Fluntern (ZUE) and Schmerikon (SME)] provided by the Swiss national weather service (Fig. 1). The observed wind data contain measurements (mean, gust) every 10 minutes. Note, that only the meteorological station Schmerikon is situated directly at the lake's shore.

\subsection{In-situ wave measurements}

The surface wave field properties simulated by SWAN were compared to the data measured by a pressure sensor between 15 Sep - 21 Oct 2009. The sensor was deployed in the near shore zone (at $\sim 2 \mathrm{~m}$ water depth) of Lake Zurich near the village of Meilen $\left(47.26^{\circ} \mathrm{N}, 8.66^{\circ} \mathrm{E}\right.$; Fig. 1$)$. Pressure measurements were made at $1 \mathrm{~m}$ below the water surface with a sampling frequency of $16 \mathrm{~Hz}$ during the entire deployment period. The time series of subsurface pressure was converted to a time series of surface elevation following the procedure as described by HOFMANN et al. (2008). Wave parameters like the significant wave height $\left(H_{s}\right)$ and the significant period $\left(T_{s}\right)$ were calculated for segments of 1,024 ( 1.1 min) samples by using the zero-upcrossing method (HOFMANN et al. 2008, IAHR 1989).

It is worthwhile to mention that wind waves growing under the action of wind typically have a slope close to $4 \%$, defined as the ratio between significant wave height $H_{s}$ and the corresponding wavelength. For instance, a wave with a period of $1.8 \mathrm{~s}$ is about $5 \mathrm{~m}$ long, which means that, if locally generated, one would expect an $H_{s}$ value close to $20 \mathrm{~cm}$. However, the waves observed at the study site in Meilen have wave heights of only a few centimeters. This implies that these waves are not locally generated, but propagate from their source region to the measurement site by increasing their wave length. Locally generated waves have short wave lengths of typically $<2 \mathrm{~m}$, which cannot be captured by our pressure sensor. In medium-sized lakes wave measurements require, due to the small wave amplitudes, very accurate pressure sensors with a high temporal resolution (minimum $8 \mathrm{~Hz}$ ). However, waves with periods $<1.2 \mathrm{~s}$ and lengths $<2 \mathrm{~m}$ could not be measured at $1 \mathrm{~m}$ below the water surface (the deployment depth of the sensor), because of the exponential decline in wave energy with depth. The accuracy of the sensor and the transformation technique applied to subsurface pressure time series allows for resolving fluctuations of water surface elevation within $1 \mathrm{~cm}$. This represents the state of the art technique in this field, which was successfully applied and validated in Lake Constance (HOFMANN et al. 2008 and SEIBT et al. 2013).

Since the model simulations are based on wind input data with a hourly resolution and therefore cannot resolve the response of wave parameters on shorter time scales, the measured wave data were averaged to an hourly resolution for the comparison.

Lake Zurich exhibits significant shipping traffic in particular during daytime. Therefore the observed wave field is affected by ship waves. The offset of $H_{s}$ between 6 and 22 MESZ (Fig. 2a) indicates that ship waves are steadily present during daytime. In order to avoid the contamination of the wind-generated wave field by ship waves, the validation in section 4 was also performed by using only wave data during the night time (22 to 6 MESZ).

\subsection{Synthetic wind gusts}

In order to test the sensitivity of the model to wind variations a simple gust simulation was applied. The algorithm creates a Weibull-distributed synthetic time series of the wind speed with a time resolution of $1 \mathrm{~s}$. Therefore, the model has to run with a time step of $1 \mathrm{~s}$. The information about the intensity of the 1-h peak gusts is taken from the COSMO-2 model (see section 2.2). The 

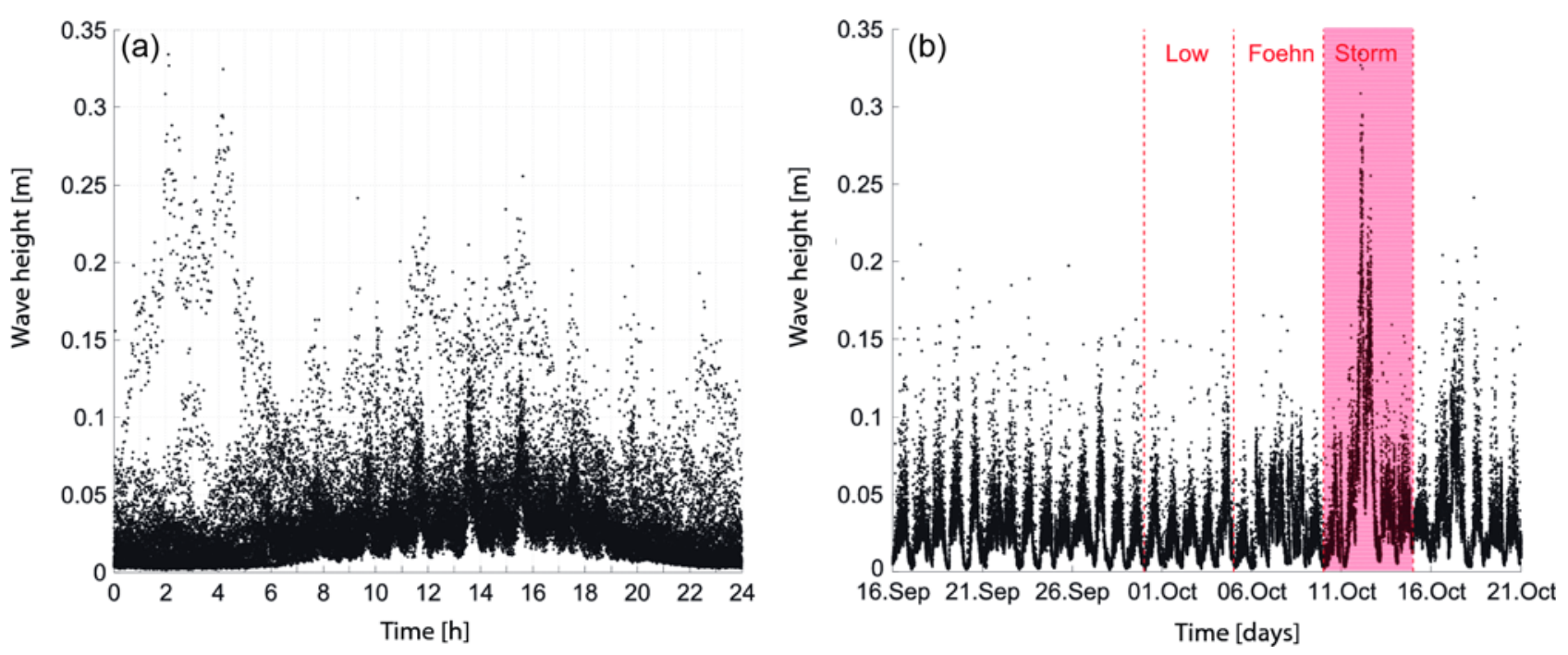

Figure 2: (a) Diurnal cycle of the wave field during the observation period (15 Sep - 21 Oct 2009). The black dots mark the individual wave measurements. The x-axis describes time of day in hours, the y-axis $H_{s}$ in $\mathrm{m}$. (b) Time series of $H_{s}$ for the overall measuring period. The red dashed lines mark the three periods which are discussed in detail in section 4 .

time series have an autocorrelation time of about $10 \mathrm{~s}$ and directional variations were neglected (see Appendix A for more details). The approach is similar to techniques used by CAVALERI and BURGERS (1992) or JANSSEN (2004). However, their time resolution was much courser ( $1 \mathrm{~min}$ and $15 \mathrm{~min}$, respectively) than ours, which is not applicable in lakes.

\section{Detailed case study - frontal passage 12 Oct 2009}

In this section we investigate the quality of the wave simulation for a storm period between 10-15 Oct 2009 marked in Fig. 2b. The driving wind field from COSMO-2 has a time resolution of 1 hour. The corresponding simulation will be referred to as REF in the following.

\subsection{Meteorological situation - quality of driving wind fields}

During 10 - 15 Oct 2009 the weather was determined by a low pressure system moving from Iceland to Eastern Europe. Its cold front moved across Lake Zurich in the early morning hours on 12 Oct 2009 (Fig. 3). The frontal passage and the hours afterward were associated with high pressure gradients which led to strong and gusty winds. The timing of the cold front passage is well captured in COSMO-2 (Fig. 3). The observed ANETZ and simulated COSMO-2 winds agree well, although mean winds at ZUE are underestimated during the period of strongest winds (Fig. 3a). Partly, this underestimation might be related to the exposure of the ANETZ station ZUE during westerly winds, an aspect which is not correctly captured in the still too coarse COSMO-2 topography. Also the intensity of the gusts in the COSMO-2 simulation agrees well with observations during this phase with slight overestimation of the gusts in SME (Fig. 3b). Finally, the wind direction was captured very well especially when the strongest winds occur (Fig. 3c). After the cold front passage in the morning, the agreement between simulated and measured winds decreases slightly. In particular, it is possible that the mean surface winds over the lake are indeed lower than implied by the ANETZ measurements. COSMO-2 captures the wind speeds at SME similarly well as at ZUE. In particular, the magnitude of the strongest winds is well simulated at SME.

\subsection{Modeled and observed surface waves on lake Zurich}

The spatial pattern of the wave field is shown in Fig. 4 during 12 Oct 2009, in steps of 2 hours. Additionally, the driving wind field is indicated with arrows. Several findings are drawn from the time evolution of the wave field: (a) the wind field over the lake is highly variable; it starts with westerly winds in the morning to a rather persistent north-westerly direction with high wind speed around noon. In the evening the wind weakens again and turns back to west wind; (b) the highest wave heights with values above $30 \mathrm{~cm}$ occur in the southern part of the lake where it is wider and hence promotes a longer wind fetch; (c) the wave field reacts to the driving wind field, of course, but in a way which would be difficult to infer from single measurement sites around the lake. Note for instance that the highest wave amplitudes are found at the southern part of the lake at 10 UTC, but it takes quite a long fetch to reach these maximum waves; (d) even a 

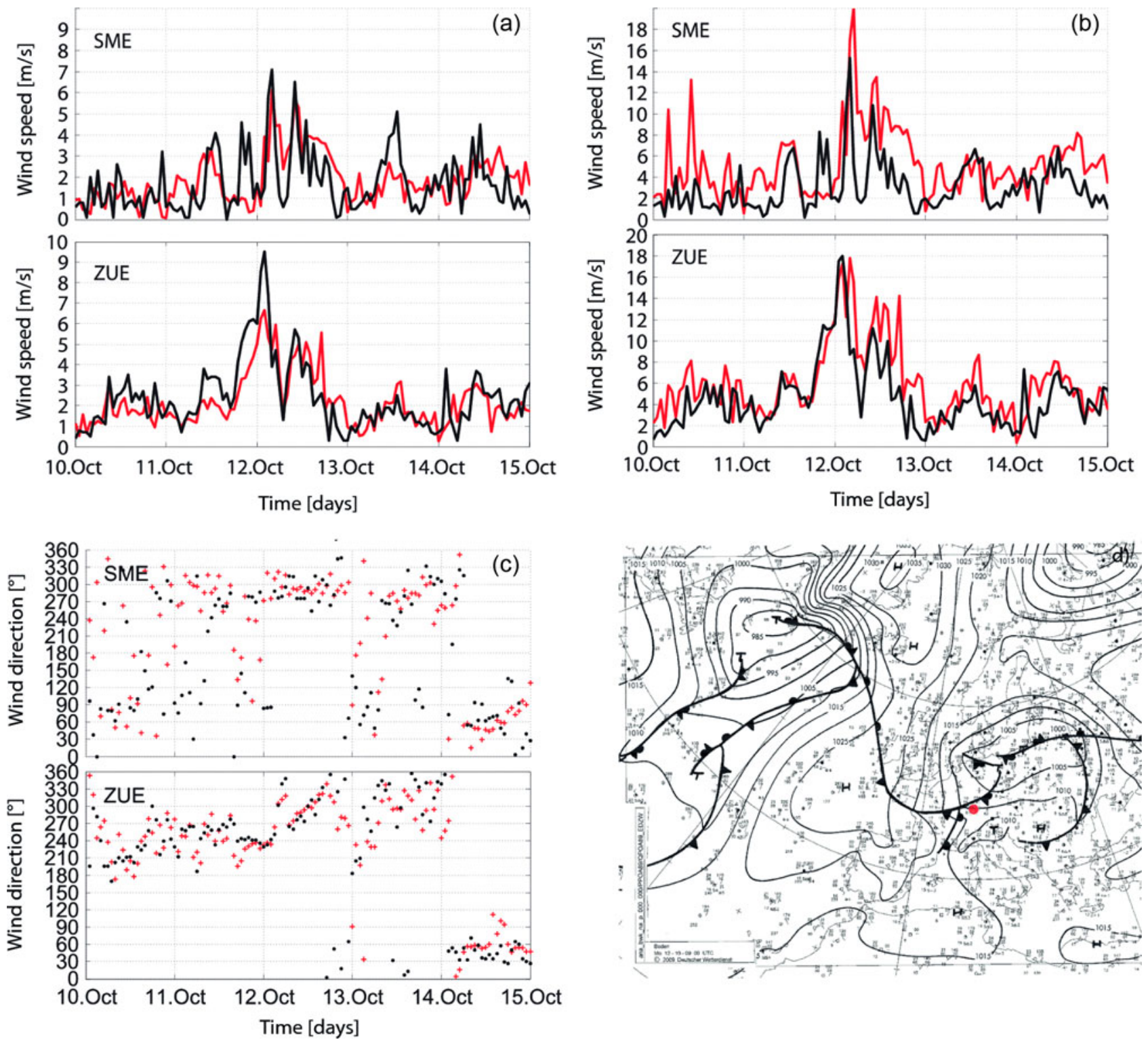

Figure 3: (a) Wind speed in $\mathrm{m} / \mathrm{s}$ at stations SME (upper panel) and ZUE (lower panel). The red lines marks the COSMO-2 output and the black lines the ANETZ measurements of the 10 min average wind speed; (b) same as a), but for wind gusts; (c) Wind direction in degrees at stations SME (upper panel) and ZUE (lower panel). The colors are the same as in Fig. a); (d) Synoptic weather chart from German Weather Service (DWD) for 00 UTC 12 Oct 2009 (taken from www.wetter3.de). The red dot marks the location of Zurich.

slight turning of the wind can go along with substantial changes in the wave field. As an example: Between 10-11 UTC (not shown) the wave maximum at the southern part builds up, as expected from the long wind fetch and the steady wind speed and direction. Between 11-12 UTC the wind experiences a transient shift in direction, which is reflected in a reduced maximum of wave heights at the southern part of the lake. The build-up of the wave field is a complex interplay between time-varying winds (time scale $1 \mathrm{~h}$ ), generation of surface waves ( 10-30 min, see Appendix B) and wave propagation and dissipation, including nonlinear effects.

The pronounced increase in $H_{s}$ during the cold front passage is well captured in all simulations, including the decrease of observed $H_{s}$ around noon of 12 Oct 2009. The measured (OBS) and simulated (REF) waves at site Meilen are compared in Fig. 5 and in Table 1. In Table 1, the mean wave height and the maximum wave amplitude $\left(H_{s}\right)$ during the storm period is given in brackets. All in all, there is a reasonable agreement between observation and the REF simulation: the peak wave amplitude is $24.1 \mathrm{~cm}$ for REF and $33.4 \mathrm{~cm}$ for OBS, i.e. the amplitude seems to be underestimated. On the other hand, the simulation clearly surpasses the mean wave height over the whole storm period, and hence is able to capture reasonably well the frontal passage's impact on the wave field. Note that the contaminating effect of ship waves (Fig. 2) is treated by 

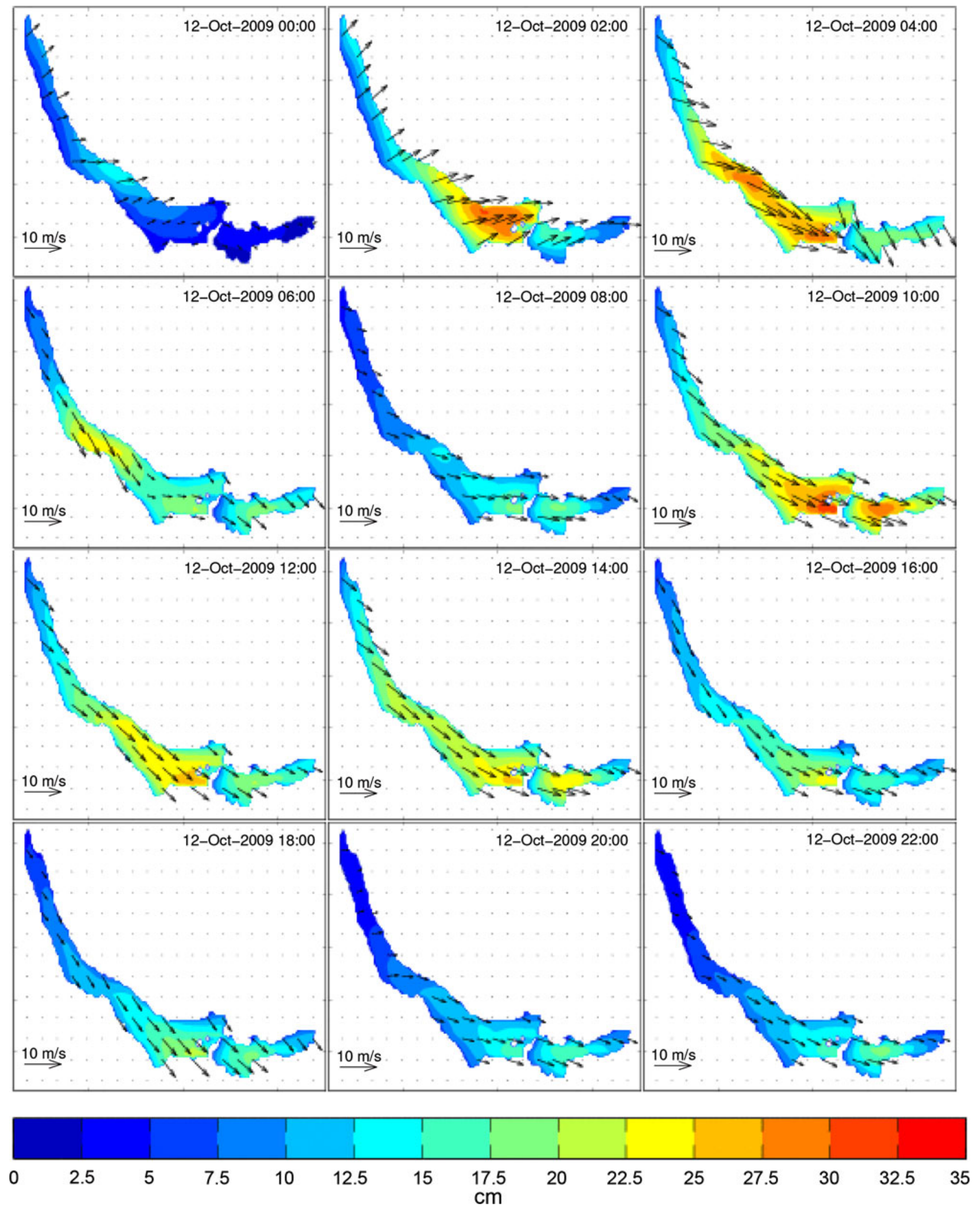

Figure 4: Mean simulated/model $H_{s}$ (in [cm], color shading) on 12 Oct 2009 in steps of $2 \mathrm{~h}$. Wind vectors from COSMO-2 are shown as black arrows.

considering the entire data and night time data only in Table 1. In a first approach, the overall time series including ship waves is taken into account. Secondly, only mea- surements during night (between 22 and 6 LST) are considered because of the then low ship activity. Both methods yield similar results. 


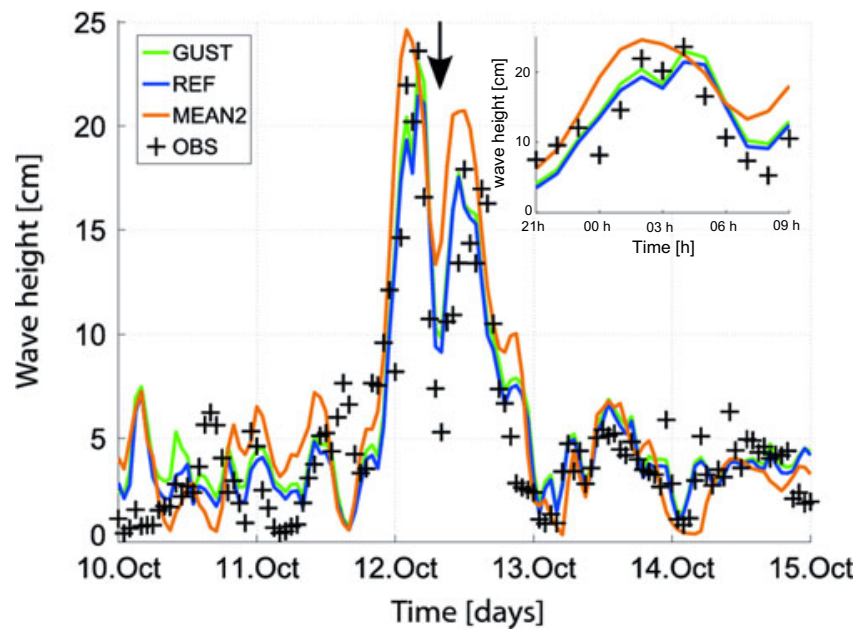

Figure 5: Time series of $H_{s}[\mathrm{~cm}]$ at the wave measurement site during the storm event. Grey crosses indicate the in-situ measurements and the three lines correspond to the simulations REF, MEAN2 and GUST (see text for details). The black arrow indicates the transient reduction of wave height in the simulation and measurements as mentioned in section 3.1. The subFig. in the upper right corner shows a zoom of the time series between 21 UTC 11 Oct 2009 and 09 UTC 12 Oct 2009.

Table 1: Mean \pm standard deviation and maximum (in brackets) of $H_{s}$ in $\mathrm{cm}$ for the period between 10-15 Oct 2009. OBS corresponds to the in-situ measurements at Meilen; REF, MEAN2 and GUST to the different SWAN simulations (see section 4 for details). The column 'Day and Night' shows the statistics for all data, the column 'Night' only for data between 22-06 LST.

\begin{tabular}{lcc}
\hline Storm event & & \\
\hline & Day and Night & Night \\
REF & $5.4 \pm 4.6(24.1)$ & $6.0 \pm 5.8(24.1)$ \\
MEAN2 & $6.0 \pm 5.9(24.6)$ & $6.4 \pm 7.2(24.6)$ \\
GUST & $5.8 \pm 4.7(26.1)$ & $6.4 \pm 6.1(26.1)$ \\
OBS & $5.1 \pm 4.9(33.4)$ & $4.9 \pm 6.5(33.4)$ \\
\hline
\end{tabular}

An interesting feature is the transient drop in wave amplitude around 08 UTC 12 Oct 2009 (see arrow in Fig. 5). This is discernible in the observation and also in the REF simulation. The reason for the drop becomes clear if the wave and wind field near the measurement site Meilen are considered in greater detail (Fig. 6). At 04 UTC (Fig. 6a) the wind came from WNW and a well developed wave field could build up with its maximum in the middle of the lake. Two hours later (Fig. 6b) the wind had turned, and the maximum wave height was shifted to the opposite shore of Meilen where the wave amplitude decreases. Again two hours later (Fig. 6c) the wind has turned back to WNW, but the wind speed is weaker than at hours before. Finally, another two hours later, at 10 UTC (Fig. 6d), the wind direction was essentially the same, hence allowing the build-up of a significant wave field.

\subsection{Impact of time resolution of driving wind fields}

The time resolution of the driving winds for SWAN is given by one of the following three scenarios: (a) 1-hour resolution COSMO-2 winds (REF, as discussed in section 3.1); (b) 2-hour COSMO-2 running means for wind speed and direction (simulation MEAN2); and (c) highresolution $(1 \mathrm{sec})$ synthetic wind speeds according to the technique presented in Appendix A (simulation GUST).

The observed double peak in the early hours is represented in REF and GUST despite the short duration, whereas in MEAN2 it is averaged out (Fig. 5). The mean $H_{s}$ over the entire storm period is $5.4 \mathrm{~cm}$ for the REF simulation (Table 1), slightly larger than the measured one. On the other hand, if peak values in $H_{s}$ are considered, the REF simulation $(24.1 \mathrm{~cm})$ is below the measured $H_{s}(33.4 \mathrm{~cm})$. The GUST simulation behaved very similar to REF with slightly higher values most of the time. In particular during the time where the highest wave heights occur, the difference between GUST and REF amounts to about $2 \mathrm{~cm}$ (Fig. 5 and Table 1). MEAN2 exhibits significantly higher values than REF, especially at higher $H_{s}$-values, which reached up to $5 \mathrm{~cm}$.

Fig. 7 compares the pattern of the wave fields for the MEAN2 and GUST simulations to REF. Focusing on the peak $H_{s}$, GUST $(26.1 \mathrm{~cm})$ leads to only slightly higher values than REF. Both underestimate OBS $(33.4 \mathrm{~cm})$ (Fig. 5, 7d and Table 1). Interestingly, MEAN2 leads to higher $H_{\mathrm{s}}$-values especially during strong winds. One would expect the opposite because peak winds are smoothed by the running mean. The reason for this behavior is the reduction of the directional variations of the winds. The directional spread of waves is accordingly reduced, which in turn leads to faster wave growth in the mean wind direction. As Meilen is situated at the northeastern shore and the wind direction is primarily from southwest, the significant wave height is increased at this site of the lake (Fig. 7a). On the other hand, the wave height is reduced at the southwestern shore, where the smoothing of the COSMO-2 winds in the MEAN2 simulation dominates over the reduction in variability of wind direction.

\section{Additional case studies}

In this section we look at two additional cases. The first case (30 Sep - 5 Oct 2009) was dominated by low pressure gradients over Switzerland. This leads to persistent weak to moderate winds over Lake Zurich, ranging between 0 and $4 \mathrm{~m} / \mathrm{s}$ (Fig. 8a, b). The COSMO-2 model winds match the ANETZ wind measurement at the three stations surrounding Lake Zurich. Both time series exhibit a clear diurnal cycle with a maximum in the afternoon (Fig 8a, b). Fig. 8c compares the simulated and measured time series of $H_{s}$ at Meilen. Several findings can be drawn: (a) except for the first day, the diurnal cycle 


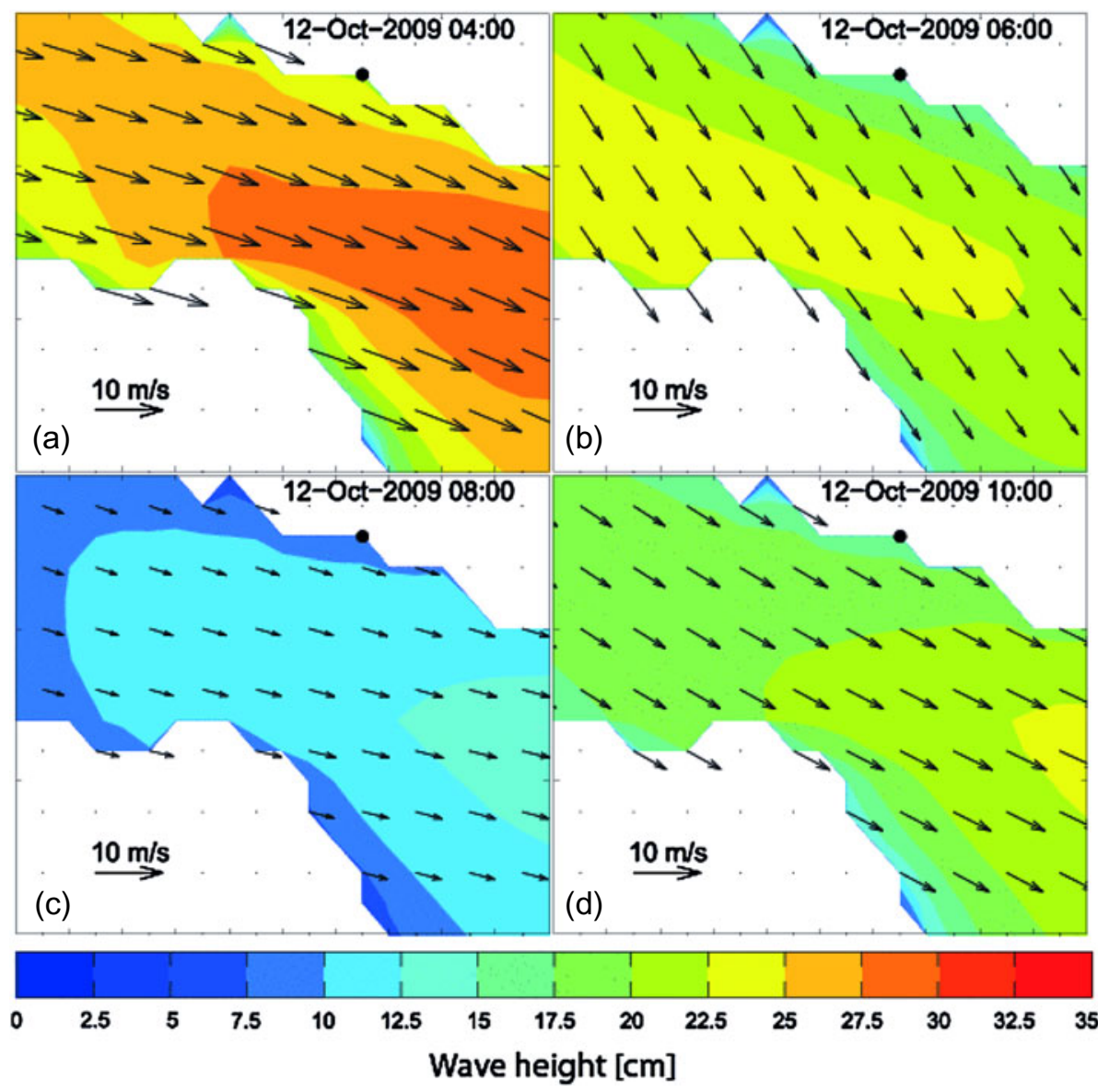

Figure 6: Mean simulated $H_{s}$ [cm] (color shading) on 04, 06, 08 and 10 UTC 12 Oct 2009. Wind vectors from COSMO-2 are shown as black arrows. The black circle marks the position of the wave measurement site.

visible in the observations is well represented in all simulations; (b) the REF simulation overestimates the mean $H_{s}$ over the whole time period by about $1 \mathrm{~cm}$ during night and by $0.1 \mathrm{~cm}$ when day and night data are used; (c) the overestimation of the mean $H_{s}$ is more pronounced in the GUST simulation and is largest in the MEAN2 simulation. Especially on the 2 Oct 2009 the overestimation of $H_{s}$ is considerable even if wind direction and speed are well captured by COSMO-2. We speculate that this is because the wind direction is around $300^{\circ}$ (not shown) which is rather parallel to the shore line. Thus, the fetch is very sensitive to small variations in the wind direction. Additionally, fine-scale structures of the shore line (e.g. small deltas or bights) are not exactly represented in the SWAN model because of its resolution. This can lead to significant different wave fields in reality compared to the model, especially when the winds are parallel to the shore line.

The second case (5-10 Oct 2009) was influenced by a low pressure system west of France. The system induces a weak Foehn flow over the Alps. In the region of interest south-easterly winds prevail occasionally, especially in the extreme southeastern corner of the lake. The period was dominated by weak mean winds $(<3 \mathrm{~m} / \mathrm{s})$, but was interspersed with transient periods of wind bursts up to
$5 \mathrm{~m} / \mathrm{s}$ over $10 \mathrm{~min}$ time periods (Fig. $8 \mathrm{a}, \mathrm{b}$ ). These bursts are not captured in the COSMO-2 simulations, although overall simulated and measured (ANETZ) mean winds agree reasonably well (Fig. 8a, b). The gusts are well represented in the COSMO-2 model (not shown), with maximum gusts up to $8 \mathrm{~m} / \mathrm{s}$ in the model and $10 \mathrm{~m} / \mathrm{s}$ in the observations. The simulated mean and maximum $H_{s}$ are slightly higher in the south-eastern part of the lake (not shown), most likely because of the frequently occurring Foehn bursts in this region (Fig. 8b). The time series of measured $H_{s}$ at site Meilen (Fig. 8c) shows many peaks, especially between 7-9 Oct 2009. These peaks have similar amplitudes $(5-8 \mathrm{~cm})$, are persistent over a long time period and are found during day and night time, hence probably they are not caused by ship traffic. The peaks in $H_{s}$ are clearly correlated with wind peaks at ZUE (see Fig. 8b). Whereas the general wind direction is from south, the peaks are associated with a wind turning towards west. In the preceding case no short-lived wave peaks occurred. We therefore interpret them as wind peaks associated with Foehn-related breakthroughs. An unambiguous conclusion in this respect would need wind measurements near the site Meilen, which are unfortunately not available. Particularly after 7 Oct 2009, the REF simulation underestimates the mean $H_{s}$. The 

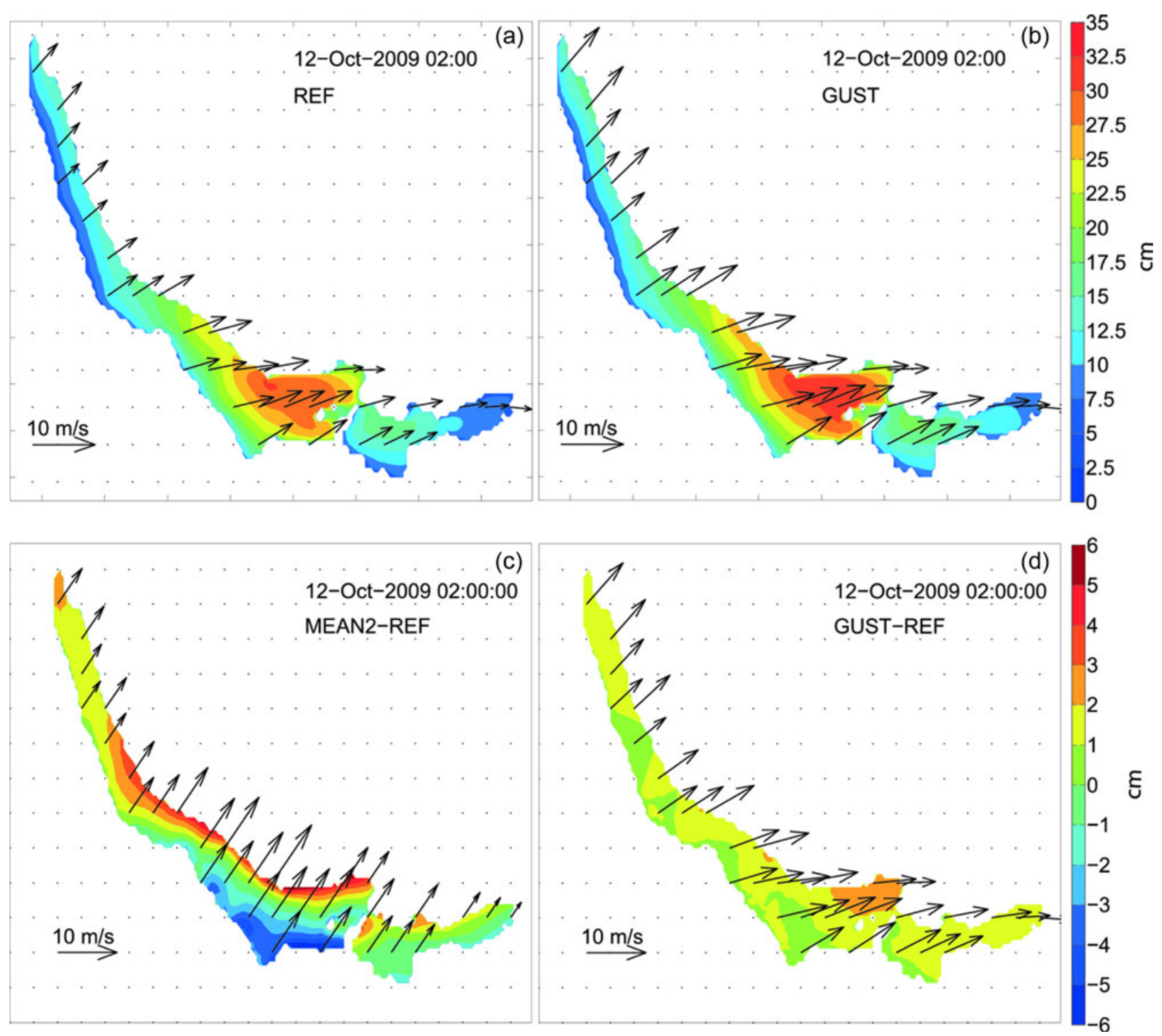

Figure 7: a,b) $H_{s}[\mathrm{~cm}]$ for the storm case in the REF and GUST simulation, respectively; c,d) Difference in $H_{s}$ between c) MEAN2 and REF and d) GUST and REF. The black arrows denote winds from the MEAN2 and GUST simulation.

underestimation is similar in the MEAN2 simulation and only slightly reduced in the GUST simulation for all and night-only data. All simulations significantly underestimate the observed peaks in $H_{s}$ (Fig. 8c) after 7 Oct 2009. This is probably caused by the afore-mentioned short-lived wind peaks missing in the COSMO-2 simulations (Fig. 8b).

The overall agreement between observed and modeled wave fields is less convincing, most likely due to deficiencies in the driving wind fields from COSMO-2. In short, the two cases illustrate the limitations of a successful wave forecast under low wind conditions.

\section{Summary}

In this work the third-generation wave model SWAN (section 2.1) was applied on the pre-Alpine Lake Zurich, which is embedded in complex terrain. The wave simulations were driven with wind data derived from the numerical weather prediction model (NWP) COSMO-2 with a horizontal resolution of $2.2 \mathrm{~km}$ (section 2.2) and were compared with observations of $H_{s}$ at one measurement site (section 2.3). The main results of the study are summarized as follows:

(a) The quality of the wave hindcast was analyzed and compared to observations for wave relevant weather situations (section 3 and 4), with particular focus on the temporal and spatial evolution of the wave field for a cold frontal passage over Lake Zurich. The driving COSMO-2 winds were taken from the NWP simulation at 1-hour intervals, as provided by the operational NWP forecast. The cold front was associated with an increase in wind speed, which is also reflected in the enhanced wave heights. Overall the 

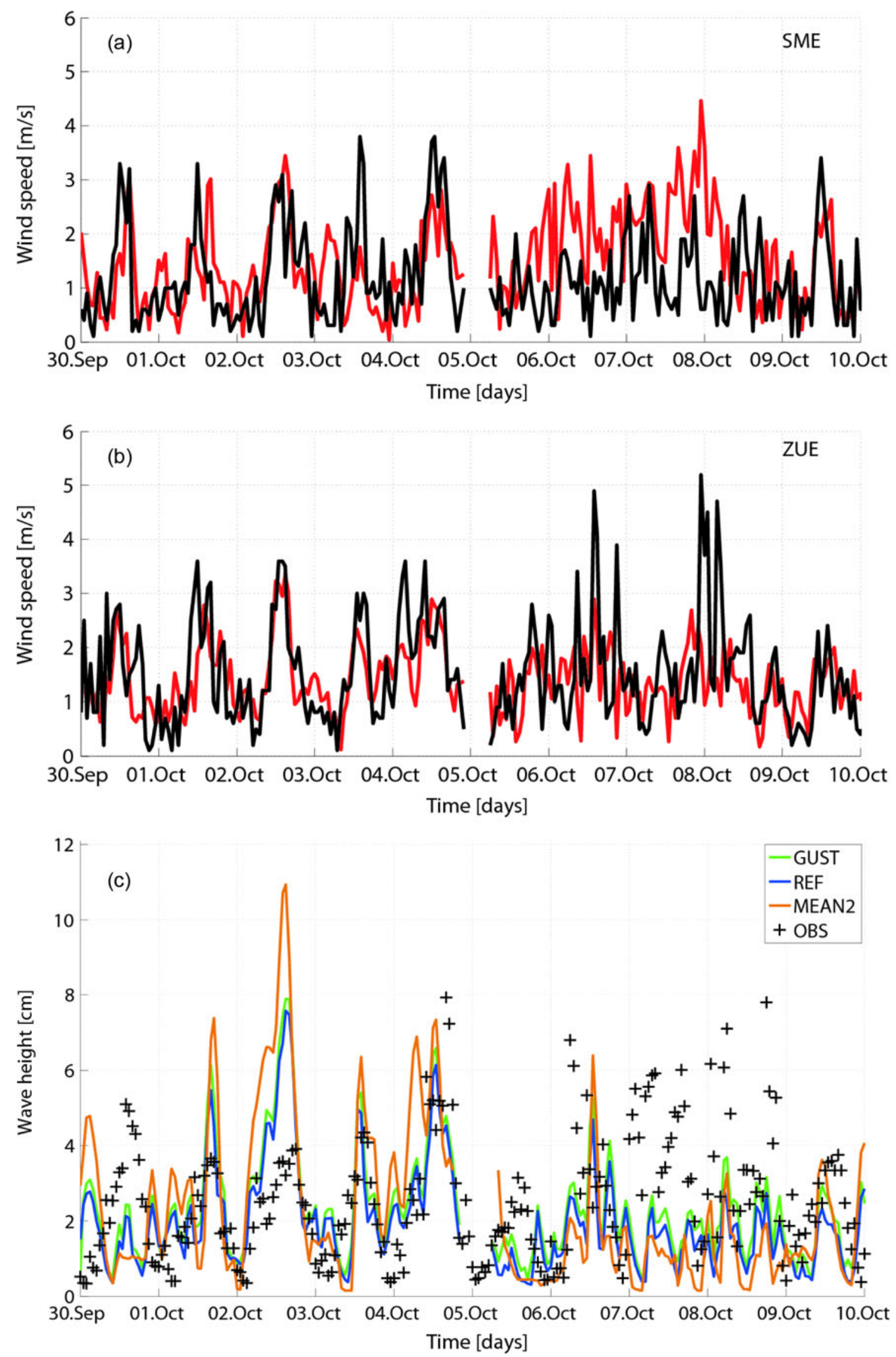

Figure 8: a) Wind speed in m/s at SME. The red lines mark the COSMO-2 output and the black lines the ANETZ measurements of the 10 min average wind speed; b) same as a) but for ZUE. c) Time series of $H_{s}$ [cm] at the study site for the low wind case and Foehn case. Grey crosses are in-situ measurements at the study site and the three lines correspond to the simulations REF, MEAN2 and GUST (see text for details). 
temporal evolution of the simulated wave height matched well with the point measurement at the near-shore site near the village Meilen, including a transient reduction in amplitude. This reduction can be traced back to a turning of the driving winds, including a decrease in wind speed, and clearly shows the potential of wave forecasts, provided the driving winds capture the essential temporal and spatial variability.

In addition two other weather situations were studied: a relatively calm situation and a Foehn flow with transient wind peaks. The diurnal cycle of the wave field is well represented for relatively calm situations. Particularly low correlations were found for the Foehn case, where COSMO-2 winds can deviate significantly from the measured winds during short periods of Foehn breakthrough (section 4). Short wind peaks over Lake Zurich are difficult to capture correctly in time and intensity in the COSMO-2 model, most likely due to the complex Alpine orography. So, even if persistent Foehn flow occurs in the major Swiss Alpine valleys, the Foehn gusts might only break through very locally and short-lived. This deficiency directly transfers to the wave forecast.

(b) It could be shown how the temporal resolution of the input wind data influences the wave forecast, in particular for the storm event. Three variations of the wind fields were considered: i) the REF simulation used COSMO-2 mean wind data with one-hourly resolution; ii) the MEAN2 simulation used 2-hour running means of COSMO-2 winds; and iii) the GUST simulation used a statistical model of synthetic gusts that accounts for short-term fluctuations in wind speed on top of the one-hourly wind data. GUST and MEAN2 exhibit faster wave growth in wind direction than REF, but GUST increases the wave height overall whereas MEAN2 also causes a reduction. The lowest agreement with the observations was found for the MEAN2 simulation. The REF and GUST simulations show significantly higher correlations. Both simulations are very similar, but during strong winds $H_{s}$ of GUST is slightly increased compared to REF (Fig. 7). However, the differences between simulations REF to GUST are much smaller than the differences between the simulations and the observations. A possible reason for that could be the neglection of short-term fluctuations of the wind direction. However, the MEAN2 simulation indicates that an increase of the variability leads to reduced wave height in regions with a larger fetch. This could even compensate the effect of slightly increased wave height in GUST. Furthermore, the gust simulation must be evaluated in context with the extra computing resources needed for and the deficiencies of the input wind data from COSMO-2. Considering these reasons, a high-resolution gust simulation seems not justified for our application.
The application of SWAN to a narrow, elongated lake in the pre-Alpine region like Lake Zurich is possible but case sensitive in terms of the predominant wind regime: a larger-scale high-wind situation was better simulated than a low-wind situation with small-scale wind systems. Reasonable wave fields can be obtained using operational 1-hourly winds from a mesoscale NWP model with $2.2 \mathrm{~km}$ mesh size. Nevertheless, more studies for additional weather situations would help to gain further insights and improve the quality of wave simulations. Moreover, the investigation of several events of the same weather situation will help to obtain results that are statistically more robust.

\section{Acknowledgments}

We thank the national Swiss weather service (MeteoSwiss) for providing access to the COSMO-2 and the ANETZ wind data.

\section{References}

Ágústsson, H., H. ÓlAFsSON, 2009: Forecasting wind gusts in complex terrain. - Meteor. Atmos. Phys. 103, 173-185.

BooiJ, N., L.H. HolthuiJSEN, R.C. RIS, 1996: The SWAN wave model for shallow water. - In: Proceedings of 24th International Conference on Coastal Engineering, Orlando 1, 668-676.

BoOIJ, N., R.C. RIS, L.H. HolthUIJSEN, 1999: A thirdgeneration wave model for coastal regions: 1 . Model description and validation. - J. Geophys. Res. 104, 7649-7666.

Brasseur, O., 2001: Development and Application of a Physical Approach to Estimating Wind Gusts. - Mon. Wea. Rev. 129, 5-25.

CAVAleri, L., G. Burgers, 1992: Wind gustiness and wave growth. - KNMI Tech. Memo. 62 pp.

Cavaleri, L., P. Malanotte-Rizzoli, 1981: Wind wave prediction in shallow water: Theory and applications. - J. Geophys. Res. 86, 961-973.

Chen, Q., H. ZHAO, K. HU, S.L. DOUglass, 2005: Prediction of wind waves in a shallow estuary. - J. Waterway, Port, Coastal Ocean Eng. 1314, 137-148.

DOMS, G., U. SCHÄTTLER, 2002: A description of the nonhydrostatic regional model LM. Part 1. Dynamics and numerics. - Deutscher Wetterdienst (DWD), Offenbach, Germany, 149 pp.

FradON, B., D. HAUSER, J.-M. LEFÈVRE, 2000: Comparison study of a second-generation and of a third-generation wave prediction model in the context of the SEMAPHORE Experiment. - J. Atmos. Oceanic Technol. 17, 197-214.

GelCI, R., H. CAZAlÉ, J. VASAL, 1956: Utilization des diagrammes de propagation à la prévision énergétique de la houle. - Bull. Inf. Com. Central Oceanogr. Etud. Côtes 8, 169-197. 
_, - _, 1957: Prévision de la houle. La méthode des densités spectroangulaires. - Bull. Inf. Com. Central Oceanogr. Etud. Côtes 9, 416-435.

Hasselmann, S., K. HasselmanN, J.H. Allender, T.P. BAMETT, 1985: Computations and parameterizations of the linear energy transfer in a gravity wave spectrum. Part II: parameterizations of the nonlinear transfer for application in wave models. - J. Phys. Oceanogr. 15, 1378-1391.

He, Y., A.H. Monahan, C.G. Jones, A. Dai, S. Biner, D. CAYA, K. WINGER, 2010: Probability distributions of land surface wind speeds over North America. - J. Geophys. Res. 115, D04103. DOI:10.1029/2008JD010708.

HeNNESSEY, J.P., 1977: Some Aspects of Wind Power Statistics. - J. Appl. Meteor. 16, 119-128.

HofmanN, H., 2008: Characteristics and implications of surface gravity waves in the littoral zone of a large lake (Lake Constance). - Ph.D. Thesis, University of Konstanz, Germany, 131 pp.

Hofmann, H., A. Lorke, F. Peeters, 2008: The relative importance of wind and ship waves in the littoral zone of a large lake. - Limnol. Oceanogr. 53, 368-380.

HolthUiJSEN, L.H., 2007: Waves in Oceanic and Coastal Waters. - Cambridge University Press, Cambridge, $387 \mathrm{pp}$.

HolthuiJSEN, L.H., et al., 2009: Swan cycle III version 40.72, user's manual. - Delft Univ. of Technology, Faculty of Civil Engineering and Geosciences, Environmental Fluid Mechanics Section, Delft.

Horn, W., C.H. Mortimer, D.J. SchwaB, 1986: Windinduced internal seiches in Lake Zurich observed and modeled. - Limnol. Oceanogr. 31, 1232-1254.

Howard, K., G. Zarillo, M. Splitt, S. LAZARUS, S. CHIAO, 2009: The impact of atmospheric model resolution on a coupled wind/wave forecast system. - Preprints, 16th Conference on Air-Sea Interaction, Phoenix, Arizona, Amer. Meteor. Soc, CD-ROM P9.2.

HUBERT, W.E., 1957: A preliminary report on numerical sea condition forecasts. - Mon. Wea. Rev. 85, 200-204.

HUTTER, K., 1983: Strömungsdynamische Untersuchungen im Zürich- und im Luganersee. Ein Vergleich von Feldmessungen mit Resultaten theoretischer Modelle. Schweiz. Z. Hydrol. 45, 101-144.

Hug, C., P. KaufmanN, D. RuffieuX, 2010: Verification of COSMO-2 with independent data from a wind profiler. COSMO Newsletter 10, 6 pp.

IAHR working group on wave generation and analysis, 1989: List of sea-state parameters. - J. Waterway, Port, Coastal Ocean Eng. 115, 793-808.

JANSSEN, P.A.E.M., 2004: The Interaction of Ocean Waves and Wind. - Cambridge University Press, $300 \mathrm{pp}$.

JAnssen, P.A.E.M., B. HANSEN, J.-R. BIDLOT, 1997: Verification of the ECMWF wave forecasting system against buoy and altimeter data. - Wea. Forecast. 12, 763-784.

JIN, K.-R., Z.-G. JI, 2001: Calibration and verification of a spectral wind-wave model for Lake Okeechobee. - J. Ocean. Eng. 28, 571-584.
KOMEN, G.J., 2004: The wave modelling (WAM) group, a historical perspective. -16 th BMRC modelling workshop: Past, present and future of numerical modelling.

Komen, G.J., S. HasselmanN, K. HASSElmanN, 1984: On the existence of a fully developed wind-sea spectrum. - J. Phys. Oceanogr. 14, 1271-1285.

Komen, G.J., L. CAVAlERI, M. DONElAn, K. HASSELMANN, S. HASSElmanN, P. JANSSEN, 1994: Dynamics and Modelling of Ocean Waves. - Cambridge University Press, $554 \mathrm{pp}$.

LiN, W., L.P. SANFord, S.E. SutTles, 2002: Wave measurement and modeling in Chesapeake Bay. - Cont. Shelf Res. 22, 2673-2686.

LIU, P.C., D.J. SCHWAB, R.E. JENSEN, 2002: Has wind wave modelling reached its limit? - J. Ocean. Eng. 29, 81-98.

MELLOR, G.L., T. YAMADA, 1974: A hierarchy of turbulence closure models for planetary boundary layers. - J. Atmos. Sci. 31, 1791-1806.

MiLES, J.W., 1957: On the generation of surface waves by shear flow. - J. Fluid Mech. 3, 185-204.

MIRONOV, D., 2007: Turbulence in the lower troposphere: Second-order closure and mass-flux modelling frameworks. Interdisciplinary Aspects of Turbulence. - Springer, 161-221.

MORTIMER, C.H., W. HORN, 1982: Internal wave dynamics and their implications for plankton biology in the Lake of Zurich. - Vier. Natur. Gesell. Zurich 127, 299-318.

OU, S.H., J.M. LiaU, T.W. HSU, S.Y. TZANG, 2002: Simulating typhoon waves by SWAN wave model in coastal waters of Taiwan. - J. Ocean. Eng. 29, 947-971.

PIERSON, W.J., G. NEUMANN, R. JAMES, 1955: Practical methods for observing and forecasting ocean waves by means of wave spectra and statistics. - H.O. Publ. 603, U.S. Navy Hydrographic Office, 284 pp.

PlANT, W.J., 1982: A relationship between wind stress and wave slope. - J. Geophys. Res. 87, 1961-1967.

RASCHENDORFER, M., 2007: A new TKE-based scheme for vertical diffusion and surface-layer transfer. - Technical Report, Deutscher Wetterdienst, Offenbach.

Ris, R.C., L.H. HolthuiJsen, N. BooiJ, 1999: A thirdgeneration wave model for coastal regions: 2. Verification, - J. Geophys. Res. 104, 7667-7681.

RO, K.S., P.G. HuNT, 2007: Characteristic Wind Speed Distributions and Reliability of the Logarithmic Wind Profile. - J. Environ. Eng. 133, 313-318.

ROBERTS, N.M., H.W. LEAN, 2008: Scale-selective verification of rainfall accumulations from high-resolution forecasts of convective events. - Mon. Wea. Rev. 136, 78-97.

ROGERS, W.E., P.A. HWANG, D.W. WANG, 2003: Investigation of wave growth and decay in the SWAN model: three regionalscale applications. - J. Phys. Oceanogr. 33, 366-389.

SCHÄTtLER, U., G. DOMS, C. SCHRAFF, 2009: A description of the non-hydrostatic regional COSMO-Model, Part VII: User's Guide. - www.cosmo-model.org.

SCHULZ, J.P., 2008: Revision of the turbulent gust diagnostics in the COSMO model. - COSMO Newsletter 8, 17-22. 
SeibT, C., F. PeEters, M. Graf, M. Sprenger, H. HOFMANN, 2013: Modeling wind waves and wave exposure of nearshore zones in medium-sized lakes. - Limnol. Oceanogr. 58, 23-26.

SHIMADA, T., O. ISOGUCHI, H. KAWAMURA, 2008: Numerical simulations of wind wave growth under coastal wind jet through the Kanmon Strait. - Wea. Forecast. 23, 11621175 .

SVERDRUP, H.U., W.H. MuNK, 1947: Wind, sea, and swell: theory of relations for forecasting. - U.S. Navy Hydrographic Office Pub. No. 601, 44 pp.

TOLMAN, H.L., 1992: Effects of numerics on the physics in a third generation wind-wave model. - J. Phys. Oceanogr. 22, 1095-1111.

\section{Appendix A}

\section{Synthetic wind gusts}

Here, a method for the simulation of synthetic wind gusts is described. This method was implemented into the SWAN wave model and applied to the three case studies discussed in sections 3 and 4.

First, we note that the dynamic wind fields of the COSMO-2 NWP model are provided hourly. At each forecast hour not only the instantaneous mean wind speed is given, but also the maximum one-second wind speed over the preceding forecast hour, which we interpreted as a peak gust. The basic idea of the gust simulation is to create a synthetic wind time series with a higher temporal resolution (typically $1 \mathrm{sec}$ ) for the time periods between the COSMO-2 forecast hours. Therefore, we derive a statistical model with a realistic distribution of wind speed and duration of wind gusts. The time series has to fulfill three constraints: (a) the wind speeds follow a Weibull distribution. Although no suitable reference for the wind speed distribution around Zurich could be found in the literature, several studies on wind power assume a Weibull distribution (HENNESSEY, 1977; RO and HUNT, 2007; HE et al., 2010); (b) the resulting time series has an auto-correlation of $10 \mathrm{sec}$ corresponding to typical wind gusts; (c) the directional gustiness of the wind is assumed to be negligible so that only the gustiness of the wind speed is taken into account.

In a second step, the parameters of the Weibull distribution have to be estimated from the COSMO-2 values for each one-hour forecast interval, i.e. from the instantaneous mean wind $\left(x_{\text {mean }}\right)$, the maximum wind speed over the preceding hour $\left(x_{\text {gust }}\right)$ and a probability $\left(p_{\text {gust }}\right)$. Here, we specify how often the threshold $x_{\text {gust }}$ is exceeded within a 1-hour interval, i.e. with a probability $p_{\text {gust }}=$ $1 / 3600$ if a timestep of $1 \mathrm{sec}$ is chosen.

The probability density function (PDF) for the Weibull distribution of wind speed $x$ is given as (Fig. A3)

$$
f(x ; \alpha, \gamma)=\alpha \gamma(\alpha x)^{\gamma-1} \exp \left[-(\alpha x)^{\gamma}\right],
$$

Tolman, H.L., D.V. ChaliKov, 1996: Source terms in a third-generation wind wave model. - J. Phys. Oceanogr. 26, 2497-2518.

TOLMAN, H.L., B. BALASUBRAMANIYAN, L.D. Burroughs, D.V. ChaliKov, Y.Y. ChaO, H.S. CHEN, V.M. GERALD, 2002: Development and implementation of wind generated ocean surface models at NCEP. - Wea. Forecast. 17, 311-333.

WAMDI Group, 1988: The WAM Model - A thirdgeneration ocean wave prediction model. - J. Phys. Oceanogr. 18, 1775-1810.

WU, J., 1982: Wind-stress coefficients over sea surface from breeze to hurricane, - J. Geophys. Res. 87, 9704-97.

where $\alpha$ is a scale parameter and $\gamma$ a shape parameter. Integration yields the cumulative distribution function (CDF) for the Weibull distribution (Fig. A3),

$$
F(x ; \alpha, \gamma)=-1 \exp \left[-(\alpha x)^{\gamma}\right],
$$

from which the probability 1-F for wind speeds over a certain threshold can be calculated if the parameters $\alpha$ and $\beta$ are given. Finally, the expectation value of the Weibull function is

$$
E(\alpha, \gamma)=\alpha^{-1 / \gamma} \cdot \Gamma\left(\frac{1}{\gamma}+1\right),
$$

$\Gamma$ is the Gamma function. With these pre-requisites, the Weibull parameters from the COSMO-2 values can mathematically be expressed as

$$
\begin{gathered}
x_{\text {mean }}=E(\alpha, \gamma)=\alpha^{-1 / \gamma} \cdot \Gamma\left(\frac{1}{\gamma}+1\right) \\
1-p_{\text {gust }}=F\left(x_{\text {gust }} ; \alpha, \gamma\right)=-1 \exp \left[-(\alpha x)^{\gamma}\right]
\end{gathered}
$$

Since no analytical solution of this system of nonlinear equations in $\alpha$ and $\gamma$ exists, the solutions were found with a numerical algorithm. As an outcome, the Weibull distribution of the wind speed is determined for a specific COSMO-2 one-hour time interval.

It is now possible to obtain synthetic wind speeds $X_{t}$ for the one-hour time interval from the afore-derived Weibull distribution. However, the wind speeds $X_{t}$ cannot be extracted randomly from the distribution because at the short sampling rate of $1 \mathrm{sec}$, the time-neighbouring wind speeds are not independent: an auto-correlation has to be taken into account (see assumption b) above). To incorporate this time dependence, we use an autoregressive (AR) process of order one, which means that only the time step $X_{t-1}$ before enters into the random process. Mathematically, the random process takes the form

$$
X_{t}=c+\varphi X_{t-1}+\varepsilon_{t},
$$




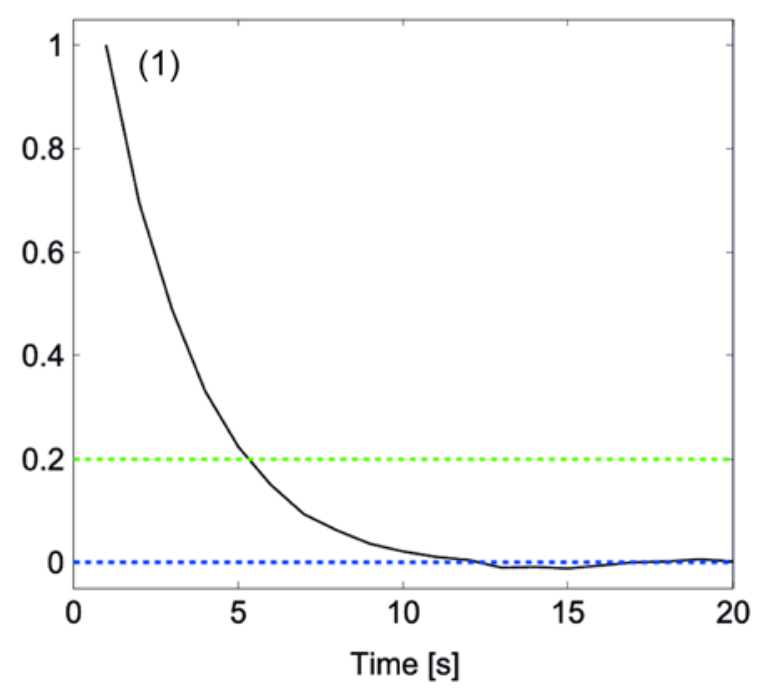

(A)
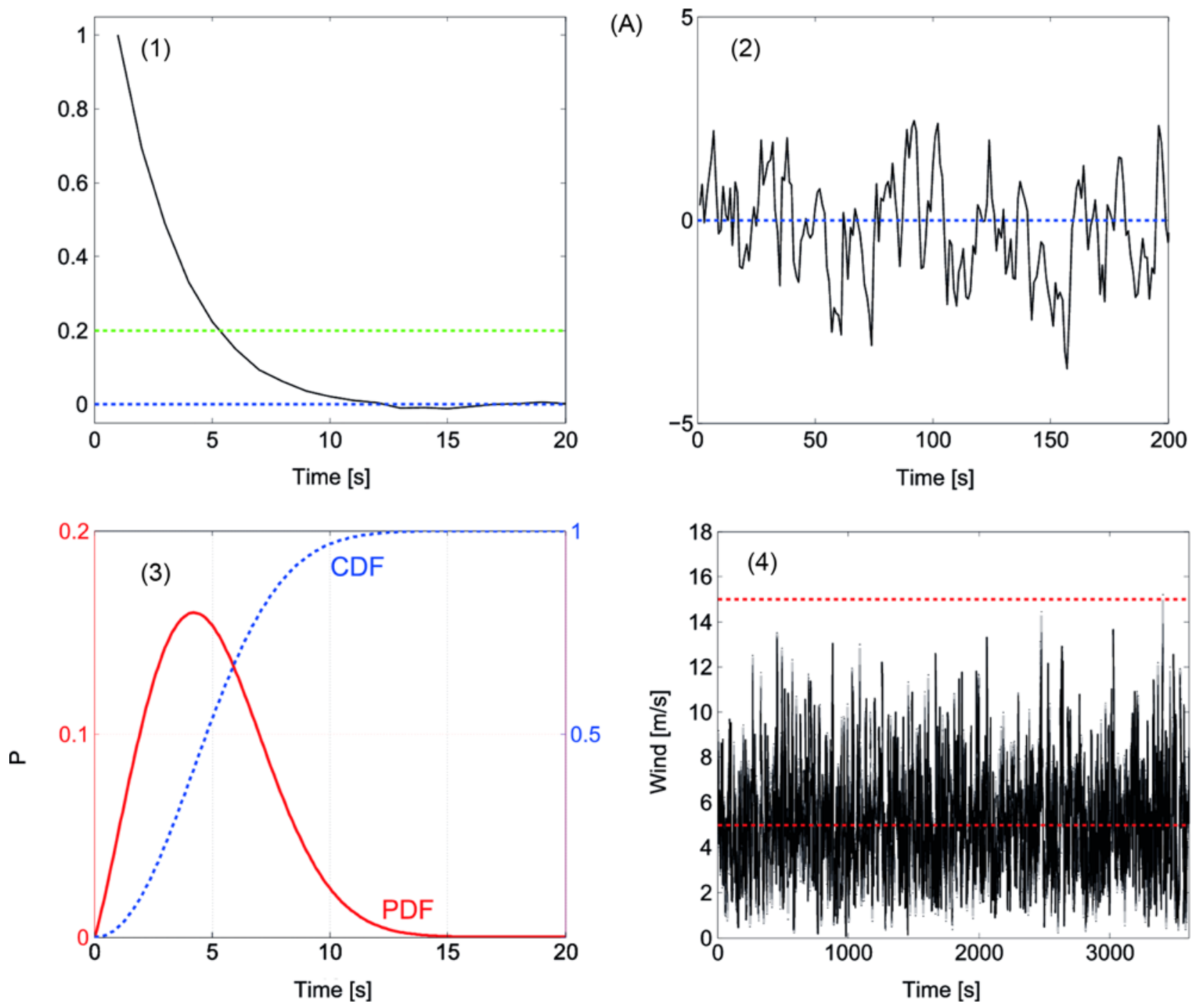

Figure A: (1) Autocorrelation of an example AR[1] process over a time period of $20 \mathrm{~s}$. (2) Time series of the same AR[1] process running over 200 seconds. (3) A Weibull distribution (red solid: PDF; blue dashed: CDF) with $x_{\text {mean }}=5 \mathrm{~m} / \mathrm{s}$ and $x_{\text {gust }}=15 \mathrm{~m} / \mathrm{s}$ with a probability $P(X$ $\left.>x_{\text {gust }}\right)=1 / 3600$. (4) Autocorrelated time series with the Weibull distribution depicted in (3). The upper red line marks $x_{\text {gust }}=15 \mathrm{~m} / \mathrm{s}$, the lower red line $x_{\text {mean }}=5 \mathrm{~m} / \mathrm{s}$.

where $c$ is a constant value, $\varphi$ the parameter of the model (the model is stationary if $|\varphi|<1$ ), $\varepsilon_{\mathrm{t}}$ is a white noise process with zero mean and variance $\sigma^{2}$ (see Fig. A2). First, a time series $X_{t}$ is produced which has the required autocorrelation time of $10 \mathrm{sec}$, but does not yet follow a Weibull distribution. The value $X_{t}$ at time $t$ depends on the value $X_{t-1}$ at time $t-1$. This causes a correlation of the values $X_{t}$ over several time steps. The value $\varphi$ is set to 0.7 , which corresponds to a correlation length of 10 time steps. As we use time steps of $1 \mathrm{sec}$ the correlation is gone after $10 \mathrm{sec}-$ onds (see Fig. A1,2), which seems to be realistic in the considered region. Second, the normally distributed $X_{t}$ are transformed to the Weibull distribution via the cumulative distribution function $\mathrm{F}(x ; \alpha, \gamma)$. Note that the autocorrelation time of $10 \mathrm{sec}$ is not altered during this transformation.

In summary, we achieve a Weibull-distributed time series $X_{t}$ of wind speeds between two COSMO-2 times where the correlation length $(10 \mathrm{sec})$ is conserved (Fig. A4).

\section{Appendix B}

\section{Sensitivity studies for the SWAN setup}

In this section the sensitivity of the wave simulation to the time step and the frequency range is investigated. The same setup as in section 2.1 is used except for the wind field at $10 \mathrm{~m}$ height, which is now taken to be uniform as $2 \mathrm{~m} / \mathrm{s}$. For the gust simulation the strength of a 1-h peak gust ( $x_{\text {gust }}$ in appendix A) is set to $5 \mathrm{~m} / \mathrm{s}$ and the mean wind is set to $2 \mathrm{~m} / \mathrm{s}$ as well.

Results for different frequencies are shown in Fig. B1, which shows the evolving wave field at Meilen from an initially calm lake. It can be noticed that an upper bound 


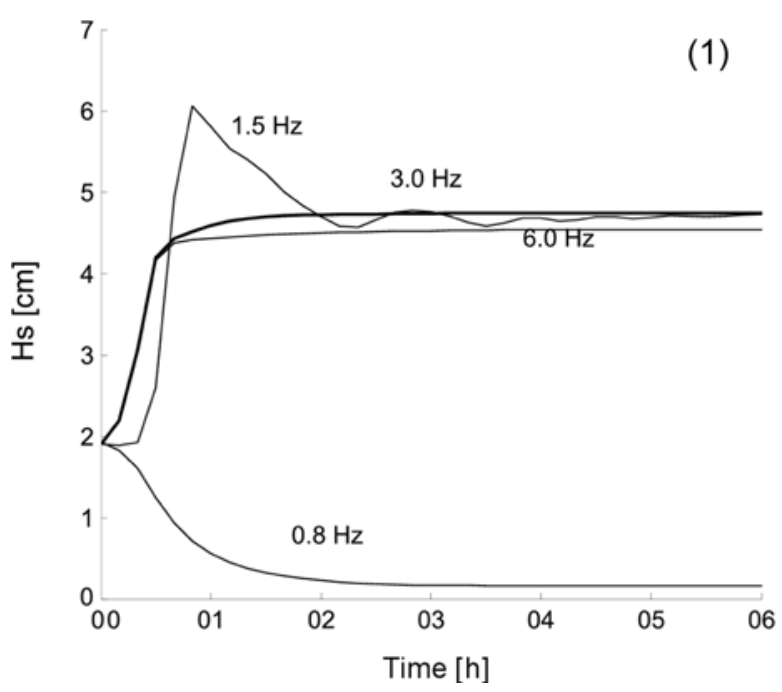

(B)

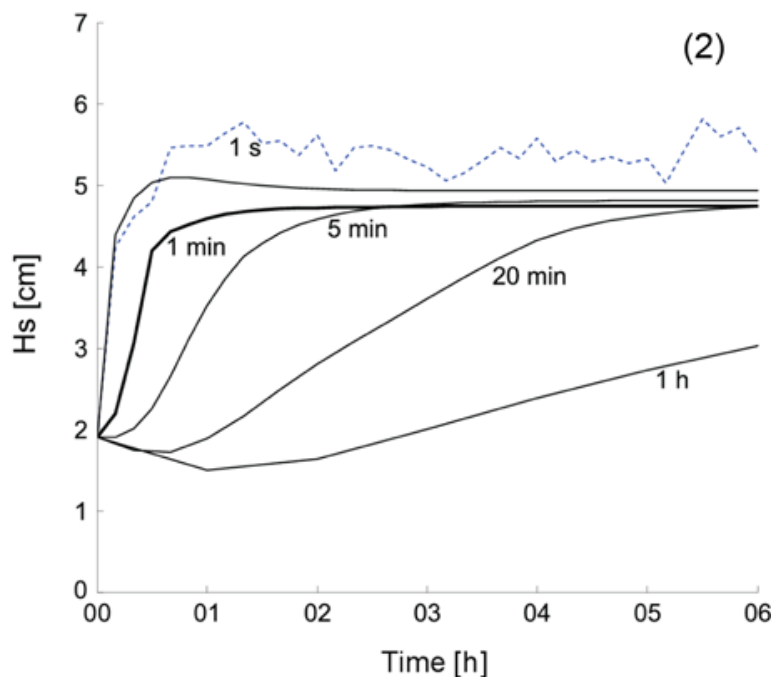

Figure B: Sensitivity analysis of the wave growth (black lines) of $H_{s}[\mathrm{~cm}]$ for a constant wind of $2 \mathrm{~m} / \mathrm{s}$. The thick line shows the configuration of the hindcast simulations in sections 3 and 4. Wave growth is shown for (1) different upper bounds of the spectral range and (2) for different simulation time steps (spectral range from 0.05 to $3.0 \mathrm{~Hz}$ ). The blue dashed line shows the simulation with synthetic wind gusts with an average wind speed of $2 \mathrm{~m} / \mathrm{s}$.

of $0.8 \mathrm{~Hz}$ does not allow any wave growth. If the value is enhanced to $1.5 \mathrm{~Hz}$, a significant overshoot is visible that is not physically meaningful. A reasonable wave growth can be achieved, if the upper threshold of the frequency is set to $3.0 \mathrm{~Hz}$ or $6.0 \mathrm{~Hz}$.

The sensitivity with respect to the time step is shown in Fig. B2. In short, a longer time step leads to a decelerated wave growth. In order to check if wave growth is realistic under the defined conditions, a theoretical calculation is performed. We assume that wave dissipation and nonlinear effects can be neglected in low wind situations and for low wave heights. For this reason only the wave generation $S_{\text {in }}$ (see section 2.1) by wind is considered based on the positive-feedback mechanism described by MILES (1957):

$$
S_{\text {in }}(f, \theta)=\beta E(f, \theta)
$$

where $E$ is the energy density for several wave components with frequency $f$ and direction $\theta$ and $\beta$ is the exponential wave growth. The parameter $\beta$ can be determined when the phase speed $c$ and the frictional velocity $\mathrm{u} *$ are known.

For simplification only a single wave component is considered with the same direction as the wind. A constant frequency of $f=2 \mathrm{~Hz}$ is assumed, which is in accordance with the initial wave field in the sensitivity experiment. With this information the phase speed $c$ in deep water can be calculated. Because the waves have a short response time, it is assumed that $c$ remains approximately constant.

$$
c=\frac{1}{f} \frac{g}{2 \pi} \cong 0.78 m / s
$$

The frictional velocity is estimated with the method of WU (1982). With this assumption a $10-\mathrm{m}$ wind $u_{10}=$ $2 \mathrm{~m} / \mathrm{s}$ leads to a frictional velocity of $u_{*} \cong 7 \mathrm{~cm} / \mathrm{s}$. Now, the exponential growth rate can be determined with the empirical relation from PLANT (1982):

$$
\beta=0.25\left(\frac{u_{*}}{c}\right) f \cong 0.004 / s
$$

Because of $E \approx H^{2}$, a doubling of the wave height $H$ requires a 4 times higher wave energy $E$. Now can be inserted into the Miles equation, which results in

$$
E(t)=E(0) \cdot e^{\beta t}
$$

Based upon this, a time of $346 \mathrm{~s}$ is calculated for the doubling of the wave height. It should be noted that with higher wave heights, wave dissipation becomes more important, which reduces the growth rate.

Fig. B2 suggests that the SWAN simulation with $1 \mathrm{~s}$ time resolution is the most realistic one. The wave amplitude becomes stationary after about $10 \mathrm{~min}$. However, a resolution of $1 \mathrm{~min}$ sufficiently captures wave growth and the wave field is established after $30 \mathrm{~min}$. Furthermore, the needed computational resources are significantly reduced. The simulations with time steps of 5 minutes and more show a wave growth that is far away from observations. The wave field needs $2 \mathrm{~h}$ and more to be stationary. The simulation with synthetic gust leads to a $10 \%$ higher stationary wave height, but the wave growth is similar to the one in the 1-s simulation with constant winds. 